\title{
More than just a problem with faces: Altered body perception in a group of congenital prosopagnosics
}

\section{Davide Rivolta, Rebecca P. Lawson \& Romina Palermo}

To cite this article: Davide Rivolta, Rebecca P. Lawson \& Romina Palermo (2016): More than just a problem with faces: Altered body perception in a group of congenital prosopagnosics, The Quarterly Journal of Experimental Psychology, DOI: 10.1080/17470218.2016.1174277

To link to this article: http://dx.doi.org/10.1080/17470218.2016.1174277

Accepted author version posted online: 06 Apr 2016.

Submit your article to this journal $₫$

山 Article views: 12

Q View related articles $\square$

View Crossmark data 5 
Publisher: Taylor \& Francis \& The Experimental Psychology Society

Journal: The Quarterly Journal of Experimental Psychology

DOI: $10.1080 / 17470218.2016 .1174277$

More than just a problem with faces: Altered body perception in a group of congenital prosopagnosics

Davide Rivolta ${ }^{1}$, Rebecca P. Lawson ${ }^{2} \&$ Romina Palermo ${ }^{3}$

1. School of Psychology, University of East London (UEL), London, UK.

2. Wellcome Trust Centre for Neuroimaging, University College London (UCL), London, UK.

3. ARC Centre of Excellence in Cognition and its Disorders, and School of Psychology, University of Western Australia, Crawley, Australia.

Word count: 4832

Running title: Altered body perception in prosopagnosia

Acknowledgments: We thank Andrew J. Calder for suggesting that we use this task to examine nonface processing in people with congenital prosopagnosia. We also wish to thank Shahad Al-Janabi for her help in collecting $\mathrm{CP}$ data.

\section{Corresponding author:}

Dr Davide Rivolta

School of Psychology, University of East London (UEL), Water Lane, E15 4LZ, London, UK

Phone: +44(0)2082234737; Email: d.rivolta@uel.ac.uk

\section{Abstract}


It has been estimated that one out of forty people in the general population suffer from congenital prosopagnosia (CP), a neurodevelopmental disorder characterized by difficulty identifying people by their faces. CP involves impairment in recognising faces, although the perception of non-face stimuli may also be impaired. Given that social interaction does not only depend on face processing, but also the processing of bodies, it is of theoretical importance to ascertain whether $\mathrm{CP}$ is also characterised by body perception impairments. Here, we tested eleven CPs and eleven matched control participants on the Body Identity Recognition Task (BIRT), a forced-choice match-to-sample task, using stimuli that require processing of body, not clothing, specific features. Results indicated that the group of CPs was as accurate as controls on the BIRT, which is in line with the lack of body perception complaints by CPs. However the CPs were slower than controls, and when accuracy and response times were combined into inverse efficiency scores (IES), the group of CPs were impaired, suggesting that the CPs could be using more effortful cognitive mechanisms to be as accurate as controls. In conclusion, our findings demonstrate CP may not generally be limited to face processing difficulties, but may also extend to body perception.

Keywords: developmental prosopagnosia, face processing, bodies, object processing. 


\section{Introduction}

Most humans can typically recognize hundreds of familiar faces with ease. However, approximately $2-3 \%$ of the general population appears to have severe difficulty recognizing familiar faces (Bowles et al., 2009; Kennerknecht et al., 2006). This condition is known as developmental or congenital prosopagnosia (CP) (Behrmann \& Avidan, 2005; Duchaine, 2000; Rivolta, Palermo, Schmalzl, \& Coltheart, 2012). Unlike acquired prosopagnosia (AP), where the person was able to recognize faces prior to suffering a brain injury (Bodamer, 1947), CP is a developmental disorder, with most affected people reporting that they were never able to recognise identity from faces. Although $\mathrm{CP}$ is not associated with evident brain lesions as in AP, structural gray-matter abnormalities in the fusiform gyrus (Behrmann, Avidan, Gao, \& Black, 2007; Garrido et al., 2009), structural abnormalities in the white-matter (Gomez et al., 2015; Song et al., 2015; Thomas, Avidan, Humphreys, Gao, \& Behrmann, 2009), and functional abnormalities in occipital and temporal face regions (Avidan et al., 2013; Rivolta et al., 2014) characterise the condition.

A long-standing question is whether CP's visual impairment is truly face selective - that is, are people with CP typically able to recognise other non-face visual stimuli, particularly when the items in the category are as similar as faces? There are 'pure cases' of $\mathrm{CP}$, in which face recognition is impaired yet the recognition of other sets of similar objects (e.g., tools, horses etc.) is typical (Duchaine and Nakayama, 2005; Duchaine et al., 2006; Nunn, Postma and Pearson, 2001). A double dissociation is also evident, with a reported case of impaired object recognition yet typical face recognition (Germine, Cashdollar, Duzel, \& Duchaine, 2010), suggesting that faces constitute a "special" type of stimuli for the human visual system (Duchaine et al., 2006). However, given the developmental nature of the condition, it is likely that some CPs will not have face-selective impairments. Many CPs do appear to have deficits with within-class object memory (Duchaine,

Germine, \& Nakayama, 2007) and object perception (Behrmann, Avidan, Marotta, \& Kimchi, 2005; Lobmaier, Bolte, Mast, \& Dobel, 2010).

Even though objects have often been used as stimuli in the prosopagnosia literature, they do not represent the ideal category for comparison, since humans are extensively exposed to faces but generally not with objects that are very similar (unless they are experts with a category such as birds or cars). This is why a small, but growing, body of research is employing human body processing tasks to investigate whether prosopagnosia is truly face specific. In fact, similarly to faces, bodies are 
very important for person recognition (Steede, Tree, \& Hole, 2007) and exhibit a consistent spatial relation between features (i.e., faces: eyes, nose, mouth; bodies: arms, torso, legs). Stimuli that have been used to probe body processing include whole bodies (i.e., bodies with heads and faces), headless bodies, faceless bodies (i.e., bodies with heads but without the face, which has been masked), and body parts only (i.e., hand, feet) (Righart \& de Gelder, 2007; Rivolta et al., 2014; Schmalzl, Zopf, \& Williams, 2012; Urgesi, Berlucchi, \& Aglioti, 2004).

When typical participants are asked to recognise or match bodies they are better with upright than inverted bodies (except when only body parts are shown). This body inversion effect (Reed, Stone, Bozova, \& Tanaka, 2003) is of a similar magnitude to that of the face inversion effect (Minnebusch, Suchan, \& Daum, 2009), thus suggesting that holistic processing (implied by inversion effects) may not be exclusive to faces (Robbins \& Coltheart, 2012). Given that holistic processing for faces can be impaired in both AP (Ramon, Busigny, \& Rossion, 2010) and CP (Palermo, Willis, et al., 2011), recent research has explored face and body processing in prosopagnosia, with the aim to ascertain whether a "general holistic mechanism" is impaired in the condition or whether "facespecific holistic mechanisms" only are impaired.

A few studies have assessed face and body processing in AP. Galen, a 31-year old man with AP, exhibited typical body detection and body identity discrimination (Susilo, Yang, Potter, Robbins, \& Duchaine, 2015). Similarly, patient PS (Rossion et al., 2003) showed typical body-selective brain responses as assessed with functional MRI (Peelen, Lucas, Mayer, \& Vuilleumier, 2009). Note that, however, in this study no control data were acquired; in addition, there was no behavioural task that directly tapped into body processing, so we cannot ascertain whether body processing was impaired or not in this patient Body processing, however, was impaired in other AP cases. Patient FM, a 35-year old male with AP, showed impaired body processing as assessed with a matching-to-sample task (Moro et a1., 2012). Furthermore, a study with a larger sample size showed that not all APs were able to discriminate bodies as well as controls (Susilo, Yovel, Barton, \& Duchaine, 2013). In summary, these studies indicate that face and body processing can sometimes be dissociated in AP and, thus, can be mediated by separated cognitive and neural mechanisms. This separation is in line with functional neuroimaging studies (see Kanwisher, 2010 for a review).

The reason why face and body processing may or may not be dissociable in AP may have an anatomical explanation. Since the proximity of functionally localized face (Gauthier et al., 2000; 
Kanwisher, McDermott, \& Chun, 1997) and body (Downing \& Peelen, 2011; Peelen \& Downing, 2005) areas, it is likely that a brain lesion encompassing different category-sensitive regions may give raise to both face and body processing deficits. On the other side, a more specific (i.e., localised) lesion will give raise mainly to face or body processing difficulties (Pitcher, Charles, Devlin, Walsh, \& Duchaine, 2009).

Given the absence of any obvious sign of brain lesion in $\mathrm{CP}$, it is an interesting question to investigate body perception in this group. Duchaine et al. (2006) reported normal body perception, as assessed with a match-to-sample task, in a single case study of CP. In addition, research with functional MRI (fMRI) demonstrated typical body activity in the body-selective regions of three CPs (Van den Stock, van de Riet, Righart, \& de Gelder, 2008), and typical face-body discrimination performance in occipito-temporal regions as assessed with multi-voxel pattern analysis (MVPA) of functional MRI (fMRI) data in a sample of six CPs (Rivolta et al., 2014). On the other hand, Righart and colleagues (2007) showed aberrant body inversion effect (i.e., lack of amplitude increase for inverted stimuli) as measured with electroencephalography (EEG) in a group of four CPs. To our knowledge, all of the above studies investigating body recognition in $\mathrm{CP}$ have used clothed stimuli. While it is the case that bodies are typically clothed in Western culture we cannot be certain whether the findings to date reflect preserved/impaired processing of clothing or cues to the body identity signaled from the clothes alone. Body processing in $\mathrm{CP}$ has also been tested using biological motion tasks, which consist in presenting dots that move (e.g., walk, dance) by following or not a human (i.e., biological) pattern of motion. Results demonstrated atypical biological motion perception in five CPs (Lange et al, 2009) (note however that the authors did not test CPs' performance on static body images). Again, the sample size in this study is small, making it difficult to generalize the conclusions to all cases of CP. In summary, body perception has only been the focus of a limited work carried out on a small number of CPs, and results are heterogeneous, possibly due to differences in the body stimuli used.

Here we investigated body processing in a sample of CPs and age-matched controls using a novel body identity recognition task (BIRT) that requires explicit recognition of body identity in the absence of clothing cues. Some of the CPs included in the current study have been previously tested by our group and performed the normal range (as measured considering accuracy scores) on object recognition tasks (Rivolta, Palermo, Schmalzl, \& Coltheart, 2012), showed typical neuromagnetic 
(MEG) activity (M170) for face and place (i.e., scene) perception (Rivolta, Palermo, Schmalzl, \& Williams, 2012), and showed typical fMRI "face-body" and "face-body parts" discrimination activity (Rivolta et al., 2014). Thus, we hypothesized a face-specific problem in our sample of CPs, which would not extend to body processing. The stimuli in this task comprised topless male bodies, such that the ability to process not only coarse body outline, but also torso shape, musculature, size, skin tone and parts (nipples, belly button), are necessary for accurate identity recognition. In this regard the stimuli are better comparable to face stimuli. We also took advantage of our relatively large sample size $^{1}$, unique to this study, to examine individual differences in body identity processing ability in CP, and how this might relate to individual difference in face processing ability.

\section{Methods}

\section{Participants}

This study received ethical approval from the Macquarie University Ethics Committee and it conforms to The Code of Ethics of the World Medical Association (Declaration of Helsinki), printed in the British Medical Journal (18 ${ }^{\text {th }}$ July 1964).

Eleven people with CP (7 Females, Mean age $=42$, Range: $22-61, \mathrm{SD}=13.30)$ and eleven people who did not report face processing impairments ( 7 Females, Mean age $=40$, Range: $23-50$, SD $=9.5$ ) completed the experiment (the two groups did not differ in age: $U(20)=67.5, \mathrm{z}=.46, p=.65$ ). All participants reported normal or corrected to normal vision, no history of neurological or psychiatric conditions and all, except one $\mathrm{CP}$, were right handed. All participants provided written consent before participation. All participants with $\mathrm{CP}$ were recruited through the online Australian Prosopagnosia Register ${ }^{2}$, where they registered because of they reported difficulties in everyday life.

\section{Diagnostic tasks}

All CPs completed a behavioural diagnostic session where face and non-face skills were assessed. The performance of each $\mathrm{CP}$ was compared to standard norms or, when not available, to a control sample that we collected. All CPs reported significant face recognition difficulties in everyday life. The CPs completed three tests of face identity recognition: (i) The MACCS Famous Face Test 2008 (Palermo, Rivolta, Wilson, \& Jeffery, 2011) (MFFT-08), which measures the famous faces identification

\footnotetext{
${ }^{1}$ Most previous group studies in CP reported data from 4-8 participants (Avidan et al., 2013; Righart \& de Gelder, 2007; Rivolta et al., 2014).

${ }^{2}$ https://www.maccs.mq.edu.au/research/projects/prosopagnosia/register
} 
abilities; (ii) The Cambridge Face Memory Test (CFMT, Duchaine \& Nakayama, 2006), which measures the memory for newly learned faces, and (iii) the Cambridge Face Perception Test (CFPT, Duchaine et al., 2007), which assesses face-matching abilities. However, because performance on these measures is sometimes ambiguous (and could result in measurement error), when possible we have also administered an alternate version of the CFMT: the CFMT-Australian (CFMT-Aus; McKone et al., 2011). Suspected CPs that performed at least 2 SD below the control mean on at least one of the three diagnostic tasks were considered as CPs and included in the study (Dalrymple \& Palermo, 2016) (see Table 1 for raw and standardised results).

Further tasks were administered to exclude that their face processing difficulties were consequence of low-level vision problems, general cognitive difficulties or impaired social functioning. All CPs showed normal contrast sensitivity as assessed by the Functional Acuity Contrast Test (FACT, Vision Sciences Research Corporation 2002) and normal color perception with the Ishihara Test for Colour Blindness (Ishihara, 1925). The Raven Coloured Progressive Matrices (Raven, Raven, \& Court, 1998) further indicated that the IQ of all participants with CP was within the normal range. None of the CPs scored within the autistic range on the Autism-Spectrum Quotient (AQ, Baron-Cohen, Wheelwright, Skinner, Martin, \& Clubley, 2001). Object processing assessed using the length, size, orientation and picture naming (long version) subtests of the Birmingham Object Recognition Battery (BORB) (Riddoch \& Humphreys, 1993) confirmed that basic object recognition skills were intact.

In summary, the everyday face recognition difficulties reported by the CPs are not due to low-level visual difficulties, low IQ, or impaired social functioning.

Body Identity Recognition Task (BIRT)

The Body Identity Recognition Task (BIRT) is a forced-choice task, which consists of 100 trials in which participants have to decide which of two headless bodies [test] matches the identity of a headless body that was previously shown for $200 \mathrm{~ms}$ [study] (Figure 1). Participants had to press one of two keyboard keys (key-1 for the body on the left or key-2 for the body on the right), and accuracy and RTs were recorded. On 50 trials the test and study bodies were presented at the same orientation, and on 50 trials test and study bodies were shown at different orientations to avoid matching of lowlevel visual features. Same orientation and different orientation trials were randomised. 
A total of five distinct male body identities (shirtless), oriented at five different angles (left $12^{\circ}$, left $6^{\circ}$, direct $0^{\circ}$, right $6^{\circ}$, right $12^{\circ}$ ) were created using DAZ Studio 3D (https://www.daz3d.com/home). On the different orientation trials the study and test images differed by a minimum of 6 and a maximum of 24 degrees determined at random. Across all trials the correct test stimulus appeared on the left and right side of the screen an equal number of times. Stimuli were presented using E-Prime (Version 2.0; Psychological Software Tools, Pittsburgh, PA) and shown on a 15-inch Wide-screen LCD Dual Boot Macintosh MacBook Pro laptop (Processor: 2.5 Ghz Intel Core 2 DuoRAM: 2048 MB DDR2) running Windows XP. Each body covered a visual angle of $8^{\circ}$ vertical and $4^{\circ}$ horizontal.

Given that in order to detect differences between typical and atypical populations it is important to not focus just on accuracy as dependent variable (Duchaine \& Garrido, 2008), in our analysis we also considered reaction times (RTs). Furthermore, in line with a previous AP group study (Susilo et al., 2012), we also calculated the inverse efficiency scores (IES), IES was calculated as: RT / accuracy (Bruyer \& Brysbaert, 2011). A non-parametric Mann-Whitney (O) test has been adopted to compare the two groups across three different behavioural measures of the BIRT: accuracy (\%), RTs and IES. For every participant, trials with RTs above or below 2 SD of the mean were considered as outliers and thus excluded from the analysis. Only correct trials were included in the RTs and IES analysis. Controls and CPs did not differ in the number of trials that was considered in the analysis (Controls: mean $=82.5, \mathrm{SD}=6.2 ; \mathrm{CPs}$ : mean $=82.9, \mathrm{SD}=5.2 ; U(20)=62, \mathrm{z}=.10, p=.95)$.

\section{Results}

Accuracy (\%) analysis did not reveal any difference between controls (mean $=87 \%, \mathrm{SD}=5.4)$ and $\mathrm{CPs}($ mean $=87 \%, \mathrm{SD}=4.9)(U(20)=60, \mathrm{z}=-.03, p=1.0)$. However, $\mathrm{CPs}($ mean $=1322 \mathrm{~ms}, \mathrm{SD}=$ 344) took Ionger than controls (mean $=920 \mathrm{~ms}, \mathrm{SD}=167)(U(20)=17, \mathrm{z}=2.86, p=.004)$. This group difference was replicated by the IES analysis, where CPs (mean $=1526 \mathrm{~ms}, \mathrm{SD}=436$ ) showed higher IES than controls (mean $=1063 \mathrm{~ms}, \mathrm{SD}=219)(U(20)=22, \mathrm{z}=2.53, p=.011)($ see Figure 2$)$.

Since in half of the trials study and test stimuli were shown in the same orientation, whereas in half of the trials they were shown in a different-orientation, we performed an extra analysis aiming to detect whether the two groups differed in the two viewing conditions. The two groups did not differ in same-orientation accuracy (Controls: mean $=85.3 \%, \mathrm{SD}=6.2$; CPs: mean $=86.9 \%, \mathrm{SD}=6.8 ; \mathrm{U}(20)$ $=52.5, \mathrm{z}=-.53, p=.60)$, and did not differ in the different-orientation accuracy (Controls: mean $=$ 
$88.9 \%, \mathrm{SD}=0.3$; CPs: mean $=87.6 \%, \mathrm{SD}=4.1 ; \mathrm{U}(20)=52, \mathrm{z}=-.56, p=.61)$. Controls and $\mathrm{CPs}$ differed in the same-orientation RTs (Controls: mean $=896 \mathrm{~ms}, \mathrm{SD}=128$; CPs: mean $=1294 \mathrm{~ms}$, SD $=304 ; \mathrm{U}(20)=10, \mathrm{z}=-3.31, p=.001$ ), and differed in the different-orientation RTs (Controls: mean $=942 \mathrm{~ms}, \mathrm{SD}=202 ; \mathrm{CPs}:$ mean $=1352 \mathrm{~ms}, \mathrm{SD}=403 ; \mathrm{U}(20)=20, \mathrm{z}=-2.66, p=.008)$. Similarly, the IES scores in the same-orientation (Controls: mean $=1059 \mathrm{~ms}, \mathrm{SD}=190$; CPs: mean $=1512 \mathrm{~ms}, \mathrm{SD}$ $=435 ; \mathrm{U}(20)=20, \mathrm{z}=-2.67, p=.008)$ and in the different-orientation (Controls: mean $=1064 \mathrm{~ms}$, SD $=240 ;$ CPs: mean $=1544 \mathrm{~ms}, \mathrm{SD}=456 ; \mathrm{U}(20)=22, \mathrm{z}=-2.53, p=.011)$ differentiated the two groups.

To check whether face and body performance was related, thus arguing in favor or against shared cognitive processing, we correlated overall BIRT performance (i.e., collapsed across sameand different- orientations) with MACCS-08, CFMT, CFPT and CCMT, for the CP group (unfortunately this data was not collected for the controls). Non-parametric correlation analyses (Spearman) highlighted statistically significant correlations between both the BIRT-accuracy and the CFMT (z-scores) $\left(\mathrm{r}_{\mathrm{s}}=0.76, p=.007\right)$ and between the BIRT-accuracy and the CFMT (raw-scores) ( $\mathrm{r}_{\mathrm{s}}$ $=0.81, p=.002$ ). There was a statistically significant positive correlation between the BIRT-accuracy and the CCMT (raw-scores) $\left(\mathrm{r}_{\mathrm{s}}=0.69, p=029\right)$, and between BIRT (accuracy) and the CCMT (zscores) $\left(\mathrm{r}_{\mathrm{s}}=0.67, \mathrm{p}=.036\right)$ (see Figure 3 ). There were not statistically significant correlations between other tasks and the BIRT (accuracy, RTs or IES), and no correlation between CFMT and CCMT accuracy (all Ps $>.05$ ).

To ensure that our RTs and IES results for the BIRT task are robust to more stringent criterion for $\mathrm{CP}$ diagnosis, we removed participants F_23 and F_31 (and matched controls) on the grounds that their diagnosis of CP was only based on (i) self-reported everyday difficulty recognising faces and (ii) significant impairment on the MFFT-08 (although note that F23 also displayed quite poor performance on CFMT-Aus and CFPT). The reduced sample of 9 CPs still showed greater RT and larger IES scores than controls: CPs are slower $(\mathrm{U} 16)=11, p=.008)$ and show higher $\operatorname{IES}(\mathrm{U}(16)=$ $14, p=.019)$ than controls. The two groups do not differ in accuracy $(\mathrm{U}(20)=38, p=0.86)$. Nonparametric correlation analyses (Spearman) highlighted statistically significant correlations between the BIRT-accuracy and the CFMT (raw-scores) $\left(\mathrm{r}_{\mathrm{s}}=.73, p=.026\right)$. No other correlation reached statistical significance. 
To further make sure that our main finding (increased RTs in CP at the BIRTS) hold, we have been very stringent and, from the 9 CPs with a confident diagnosis (i.e., impaired on at least 2 tasks) we further excluded M_60 (who did not have a CCMT score) and M_57 (who performed below the mean). Overall, we thus compared the performance of 7 pure CPs (i.e., without object memory problems) against the performance of 7 matched controls. Results indicate that CPs were slower than controls $(\mathrm{U}(12)=6, p=.018)$, and had a trend towards longer IES $(\mathrm{U}(12)=10, p=.064)$. Nonparametric correlation analyses (Spearman) highlighted statistically significant correlations between the BIRT-accuracy and the CFMT (raw-scores) $\left(\mathrm{r}_{\mathrm{s}}=.84, p=.017\right)$ and between the BIRT-accuracy and the CFMT (z-scores) $\left(\mathrm{r}_{\mathrm{s}}=.76, p=.049\right)$. No other correlation reached statistical significance.

\section{Discussion}

In the current study we tested eleven CPs and matched control subjects on a body identity recognition task (BIRT). Results indicated that, as a group, CPs show typical accuracy on the BIRT. However, given that the analysis of RTs can be more sensitive when comparing typical and atypical populations (Duchaine \& Garrido, 2008), we analysed RTs and IES in CPs and controls. Data demonstrated slowed RTs and increased IES. Thus, CP may not be limited to face processing difficulties, but it can also extend to body processing. So far, the only $\mathrm{CP}$ study reporting typical behavioural body processing, as assessed with static faces as in our study, is limited to a single-case study (Duchaine, Yovel, Butterworth, \& Nakayama, 2006). We note, however, that CP is a heterogeneous condition (Schmalzl, 2007; Schmalzl, Palermo, \& Coltheart, 2008), so is possible that some of our CPs were impaired and some were not.

The typical accuracy on the BIRT aligns with the lack of body perception difficulties of CP in everyday life. However, the atypical RTs/IES suggests that CPs may be employing different cognitive/neural mechanisms. This might be reflected by the atypical EEG markers of face and body processing seen in CP (Righart \& de Gelder, 2007). Impaired body processing on the BIRT fits less well with recent fMRI work from our group, where six out of the eleven subjects tested showed typical "face-body" and "face-body part" MVPA discrimination (Rivolta et al., 2014). However, this difference is likely to be due to the nature of the task - in our previous fMRI study participants engaged in a one-back-task that did not specifically target body matching skills. 
At the theoretical level, our results indicate that face processing skills are not the sole perceptual ability affected by $\mathrm{CP}$, and thus this disorder may not be best characterized as entirely faceselective at the group level. In particular, when we use body stimuli that are more comparable to well controlled face stimuli, we see impairments, in contrast to studies that show intact body identity processing (Duchaine et al., 2006). This suggests that previously reported body identity difficulties in $\mathrm{CP}$ are not solely due to difficulties using clothing as cues to person identity. We have to note, however, that $\mathrm{CP}$, as a developmental disorder is very heterogeneous (see, for instance, also autism) and it is likely that some CPs will show face-selectivity (e.g., Duchaine et al., 2006) and others not (e.g., Behrmann, et al., 2005). Future studies would benefit from including a number of object categories and bodies (Susilo et al., 2012) and see whether such non-face deficits are more pronounced for social stimuli (such as bodies) over other man-made object categories.

These results may seem in disagreement with previous data showing that typical subjects are poor when they have to identify people in real life situations (i.e., on CCTV cameras) by their body only (Burton, Wilson, Cowan, \& Bruce, 1999), whereas prosopagnosics may heavily rely on extrafacial cues such as clothes and gait for person perception. We argue that the BIRT better taps into body-perception processing than previous real-life studies since we engaged body-sensitive, and not cloths-sensitive, processing. Thus, it is possible that body processing difficulties are hidden in real-life situations where CPs may rely on clothes and gait. Future studies will clarify the issue.

These shared behavioural deficits for faces and bodies may have an anatomical origin. Previous studies in CP have shown structural (Behrmann et al., 2007; Garrido et al., 2009) and functional (Avidan et al., 2013, Zhang, Liu, \& Xu, 2015) abnormalities in the fusiform gyrus, within the ventral surface of the temporal lobe. This region of the ventral visual system contains face- (fusiform face area - FFA) (Kanwisher et al., 1997), body- (fusiform body area - FBA) (Downing, Jiang, Shuman, \& Kanwisher, 2001) and scene- (parahippocampal place area - PPA) (Epstein \& Kanwisher, 1998) sensitive regions, which are activated for the typical processing of their preferred category (Kanwisher, 2010). Since these regions are very close to each other, it is possible that neurodevelopmental changes affecting CP can sometimes, albeit not always, affect both face and body processing.

This association of deficits is in line with evidence indicating that some CPs also have problems in spatial navigation (Lee, Duchaine, Wilson, \& Nakayama, 2010). In fact, since PPA and 
FFA are very close in the fusiform gyrus, it may be that anatomical/functional aberrations encompassing both areas may lead to spatial navigation problems in some, albeit not all, CPs. By following this line of thought, we may expect future cases of developmental body-agnosia (which have not been reported yet), which will be in line with published cases of selective "developmental topographical disorientation" (potentially due to PPA involvement) (Iaria, Bogod, Fox, \& Barton, 2009).

Another finding of the current study is that accuracy on the CFMT correlates with the accuracy on the BIRT. No studies of $\mathrm{CP}$ to date have had a large enough sample size to explore the ability to predict performance on one task on the basis of performance on another task. Inter-individual differences (within and between groups) are often seen as a source of noise in behavioral experiments, which typically report differences in means between conditions or groups (Kanai \& Rees, 2011). The fact that adults with CP who are more impaired at the CFMT also show less accuracy on the BIRT suggests, for the first time, that a common neural mechanism, or at least cognitive strategy, may underlie face and body processing in CP.

Both the BIRT and the CFMT involve perceiving and holding in memory a complex social stimulus in order to match to one of many possible study images. It may be the case that the 'memory' demands imposed by both tasks reflect the common cognitive component that makes performance in one social-perceptual domain/predictive of individual performance on the other social-perceptual domain. It is interesting that BIRT performance did not correlate with the CFPT (a match to sample test similar in structure to the BIRT), which could be due differing perceptual task demands despite similar task structure. Moreover, the fact that performance on the BIRT does not correlate with the MFFT-08 suggests that the cognitive processes involved in recognizing highly familiar social stimuli (in this case faces) is not related to the ability to recognize newly encountered bodies in CP.

We note, however, that a weakness of the current study is that the correlational results applied only for CPs, and they may, thus, not apply to the general population. Future studies could investigate inter-individual differences in body and face processing across CP and control participants. Such an approach may allow for the identification of a CP 'spectrum' (much like the autism spectrum) reflecting individual differences in face and body processing across the neurotypical and CP population. A potential limitation of our study is that longer RTs found in CP may be due to a general speed reduction (i.e., not specific for body processing). However, we do not think that a general 
reduction in cognitive speed can fully explain our results because CPs were also impaired with IES, which takes accuracy and RTs into account, thus excluding speed-accuracy tradeoffs. In addition, ten out of the eleven CPs in this study also completed two further face tasks: the Glasgow Face Matching Task, which measures unfamiliar face-matching abilities (Burton, White, \& McNeill, 2010), and the Local Heroes Test, which measures familiar and unfamiliar face matching (White et al., submitted); the two groups do not differ in RTs. Furthermore, the ten CPs who completed the CCMT were not slower than ten matched controls on the same task ${ }^{3}$. Overall, these results suggest that CPs' slower RTs for BIRT are specific to body perception, and are not part of a broader problem in the visual processing stream.

What does increased $\mathrm{RT}$ in the $\mathrm{CP}$ group mean on a task like the BIRT? Delayed match to sample ("X-AB" discrimination tasks), are standard both in the face and body processing literature in which it is common to consider RTs in the discussion of the findings (e.g., Duchaine et al., 2006; Moro et al., 2012; Susilo et al., 2013). Furthermore, a very similar task (with similar results) has been used to infer face discrimination difficulties in CP (Avidan \& Behrmann, 2008). Performance on the BIRT depends on perceptual and memory processes (Calder et al., 1996), since X has to be perceived and held in memory for comparison to A and B, arguably both important features of body processing. Fast and sequential presentation of images additionally ensures that low-level visual cues cannot be relied upon to perform the task (i.e. correct performance necessitates high-level global processing of body identity).

In controlling for 'duration of scrutiny' (i.e. not allowing participants view the ' $\mathrm{X}$ ' image openendedly) means that we can infer that, with the same quality and duration of visual information, $\mathrm{CP}$ individuals require substantially longer to achieve the same discrimination accuracy as controls. Furthermore, performance in the BIRT is not at ceiling $-87 \%$ accuracy provides room for participants to improve. If it was the case that the CPs took longer to perform better than controls then this result would simply represent a speed-accuracy trade off. However, here the $\mathrm{CP}$ group take longer to perform as well as the controls - which certainly suggests that they're impaired on either the perceptual or memory processes required to perform the task. In addition, as noted above, since BIRT

\footnotetext{
${ }^{3}$ Non-parametric analysis (Mann-Whitney U test) showed that RTs in controls (Mean: $5030 \mathrm{~ms}$, SD: 816) and CPs (Mean: $5582 \mathrm{~ms}, \mathrm{SD}: 860)$ did not differ $(p=.165)$.
} 
accuracy was high (i.e., $>80 \%$ ), we calculated the IES, which takes into consideration accuracy and RTs, to correct RT's for accuracy and CPs are impaired on this measure.

In conclusion, we report the first description of body processing abnormalities in a relatively large group of CPs using stimuli that require processing of body, not clothing, specific features. Additionally we are able to show that in the $\mathrm{CP}$ group inter-individual differences in body processing ability are able to predict face processing ability as measured by the CFMT. These results suggest that a similar cognitive, and possibly neural, processes underlie face and body processing difficulties in CP. Since group differences were not detected when relying on accuracy data only, our results also demonstrated that RTs and IES can represent more sensitive indices researchers can use to individuate group differences. 


\section{References}

Avidan, G., \& Behrmann, M. (2008). Implicit familiarity processing in congenital prosopagnosia. Journal of Neuropsychology, 2, 141-164.

Avidan, G., Tanzer, M., Hadj-Bouziane, F., Liu, N., Ungerleider, L. G., \& Behrmann, M. (2013). Selective Dissociation Between Core and Extended Regions of the Face Processing Network in Congenital Prosopagnosia. Cereb Cortex. doi: 10.1093/cercor/bht007

Baron-Cohen, S., Wheelwright, S., Skinner, R., Martin, J., \& Clubley, E. (2001). The autismspectrum quotient (AQ): Evidence from Asperger syndrome/high-functioning autism, males and females, scientists and mathematicians. Journal of Autism and Developmental Disorders, $31(1), 5-17$.

Behrmann, M., \& Avidan, G. (2005). Congenital prosopagnosia: Face-blind from birth Trends in Cognitive Neuroscience, 9, 180-187.

Behrmann, M., Avidan, G., Gao, F., \& Black, S. (2007). Structural imaging reveals anatomical alterations in inferotemporal cortex in congenital prosopagnosia. Cereb Cortex, 17, 23542363.

Behrmann, M., Avidan, G., Marotta, J. J., \& Kimchi, R. (2005). Detailed Exploration of Face-related Processing in Congenital Prosopagnosia: 1. Behavioral Findings. J Cogn Neurosci, 17(7), 1130-1149.

Bodamer, J. (1947). Die Prosop-agnosie. Archiv fur Psychiatrie und Nervkrankheiten, 179, 6-53.

Bowles, D. C., McKone, E., Dawel, A., Duchaine, B., Palermo, R., Schmalzl, L., . . Yovel, G. (2009). Diagnosing prosopagnosia: Effects of aging, sex, and participant-stimulus ethnic match on the Cambridge Face Memory Test and Cambridge Face Perception Test Cogn Neuropsychol, 26(5), 423-455.

Bruyer, R., \& Brysbaert, M. (2011). Combining Speed and Accuracy in Cognitive Psychology: Is the Inverse Efficiency Score (IES) a Better Dependent Variable than the Mean Reaction Time (RT) and the Percentage Of Errors (PE)? Psychologica Belgica, 51, 5-13.

Burton, A. M., White, D., \& McNeill, A. (2010). The Glasgow Face Matching Test. Behav Res Methods, 42(1), 286-291. doi: 10.3758/brm.42.1.286

Burton, A. M., Wilson, S., Cowan, M., \& Bruce, C. (1999). Face recognition in poor-quality video: Evidence from security surveillance. Psychological Science, 10(3), 243-248. 
Dalrymple, K. A., \& Palermo, R. (2016). Guidelines for studying developmental prosopagnosia in adults and children. Wiley Interdiscip Rev Cogn Sci, 7(1), 73-87. doi: 10.1002/wcs.1374

Downing, P. E., Jiang, Y., Shuman, M., \& Kanwisher, N. (2001). A cortical area selective for visual processing of the human body. Science, 293, 2470-2473.

Downing, P. E., \& Peelen, M. V. (2011). The role of occipitotemporal body-selective regions in person perception. Cogn Neurosci, 2(3-4), 186-203. doi: 10.1080/17588928.2011.582945

Duchaine, B. (2000). Developmental prosopagnosia with normal configural processing. Neuroreport, 11(1), 79-83.

Duchaine, B., \& Garrido, L. (2008). We're getting warmer--characterizing the mechanisms of face recognition with acquired prosopagnosia: a comment on Riddoch et al. (2008). Cogn Neuropsychol, 25(5), 765-768. doi: 10.1080/02643290802092102

Duchaine, B., Germine, L., \& Nakayama, K. (2007). Family resemblance. Ten family members with prosopagnosia and within-class object agnosia. Cogn Neuropsychol, 24, 419-430.

Duchaine, B., \& Nakayama, K. (2006). The Cambridge Face Memory Test: Results for neurologically intact individuals and an investigation of its validity using inverted face stimuli and prosopagnosic participants. Neuropsychologia, 44(4), 576-585.

Duchaine, B., Yovel, G., Butterworth, E. J., \& Nakayama, K. (2006). Prosopagnosia as an impairment to face-specific mechanisms: Elimination of the alternative hypotheses in a developmental case. Cogn Neuropsychol, 23(5), 714-747.

Epstein, R. A., \& Kanwisher, N. (1998). A cortical representation of the local visual environment. Nature, 392, 598-601.

Garrido, L., Furl, N., Draganski, B., Weiskopf, N., Stevens, J., Chern-Yee Tan, G., . . Duchaine, B. C. (2009). Voxel-based morphometry reveals reduced grey matter volume in the temporal cortex of developmental prosopagnosics. Brain, 132, 3443-3455.

Gauthier, I., Tarr, M. J., Moylan, J., Skudlarski, P., Gore, J. C., \& Anderson, A. W. (2000). The fusiform "face area" is part of a network that processes faces at the individual level. $J \operatorname{Cog} n$ Neurosci, 12, 495-504.

Gomez, J., Pestilli, F., Witthoft, N., Golarai, G., Liberman, A., Poltoratski, S., . . Grill-Spector, K. (2015). Functionally defined white matter reveals segregated pathways in human ventral 
temporal cortex associated with category-specific processing. Neuron, 85(1), 216-227. doi: 10.1016/j.neuron.2014.12.027

Iaria, G., Bogod, N., Fox, C. J., \& Barton, J. J. (2009). Developmental topographical disorientation: case one. Neuropsychologia, 47(1), 30-40. doi: 10.1016/j.neuropsychologia.2008.08.021

Ishihara, S. (1925). Tests for Colour-Blindness (5th ed.). Tokyo: Kanehara.

Kanwisher, N. (2010). Functional specificity in the human brain: A window into the functional architecture of the mind. Proceedings of the National Academy of Science USA, 107(25), 11163-11170.

Kanwisher, N., McDermott, J., \& Chun, M. M. (1997). The fusiform face area: A module in human extrastriate cortex specialized for face perception. Journal of Neuroscience, 17, 4302-4311.

Kennerknecht, I., Grueter, T., Welling, B., Wentzek, S., Horst, J., Edwards, S., \& Grueter, M. (2006). First Report of Prevalence of Non-Syndromic Hereditary Prosopagnosia (HPA). American Journal of Medical Genetics Part A, 140A, 1617-1622.

Lange, J., de Lussanet, M., Kuhlmann, S., Zimmermann, A., Lappe, M., Zwitserlood, P., \& Dobel, C. (2009). Impairments of biological motion perception in congenital prosopagnosia. PLoS One, 40(10), e7414. doi:7410.1371/journal.pone.0007414.

Lee, Y., Duchaine, B. C., Wilson, H. R., \& Nakayama, K. (2010). Three cases of developmental prosopagnosia from one family: Detailed neuropsychological and psychophysical investigation of face processing. Cortex, 46(8), 949-964.

Lobmaier, J. S., Bolte, J., Mast, F. W., \& Dobel, C. (2010). Configural and featural processing in humans with congenital prosopagnosia. Advances in Cognitive Psychology, 6, 23-34.

McKone, E., Hall, A., Pidcock, M., Palermo, R., Wilkinson, R. B., Rivolta, D., . . O'Connor, K. B. (2011). Face ethnicity and measurement reliability affect face recognition performance in developmental prosopagnosia: Evidence from the Cambridge Face Memory Test - Australian. Cogn Neuropsychol, 28(2), 109-146.

Minnebusch, D. A., Suchan, B., \& Daum, I. (2009). Losing your head: behavioral and electrophysiological effects of body inversion. J Cogn Neurosci, 21(5), 865-874. doi: 10.1162/jocn.2009.21074

Moro, V., Pernigo, S., Avesani, R., Bulgarelli, C., Urgesi, C., Candidi, M., \& Aglioti, S. M. (2012). Visual body recognition in a prosopagnosic patient. Neuropsychologia, 50(1), 104-117. 
Palermo, R., Rivolta, D., Wilson, C. E., \& Jeffery, L. (2011). Adaptive face space coding in congenital prosopagnosia: Typical figural aftereffects but abnormal identity aftereffects. Neuropsychologia, 49, 3801-3812.

Palermo, R., Willis, M. L., Rivolta, D., McKone, E., Wilson, C. E., \& Calder, A. J. (2011). Impaired holistic coding of facial expression and facial identity in congenital prosopagnosia. Neuropsychologia, 49, 1226-1235.

Peelen, M. V., \& Downing, P. E. (2005). Selectivity for the human body in the fusiform gyrus. $J$ Neurophysiol, 93, 603-608.

Peelen, M. V., Lucas, N., Mayer, E., \& Vuilleumier, P. (2009). Emotional attention in acquired prosopagnosia. Soc Cogn Affect Neurosci, 4(3), 268-277. doi: 10.1093/scan/nsp014

Pitcher, D., Charles, L., Devlin, J. T., Walsh, V., \& Duchaine, B. (2009). Triple dissociation of faces, bodies, and objects in extrastriate cortex. Current Biology, 19, 319-324.

Ramon, M., Busigny, T., \& Rossion, B. (2010). Impaired holistic processing of unfamiliar individual faces in acquired prosopagnosia. Neuropsychologia, 48(4), 933-944. doi: 10.1016/j.neuropsychologia.2009.11.014

Raven, J., Raven, J. C., \& Court, J. H. (1998). Section 4: The Advanced Progressive Matrices Manual for Raven's Progressive Matrices and Vocabulary Scales. San Antonio: Harcourt Assessment.

Reed, C. L., Stone, V. E., Bozova, S., \& Tanaka, J. (2003). The body-inversion effect. Psychol Sci, 14(4), 302-308.

Riddoch, M. J., \& Humphreys, G. W. (1993). BORB: The Birmingham Object Recognition Battery. Hove, UK. Lawrence Erlbaum Associates.

Righart, R., \& de Gelder, B. (2007). Impaired face and body perception in developmental prosopagnosia. Proceedings of the National Academy of Science USA, 104(43), 17234-17238.

Rivolta, D., Palermo, R., Schmalzl, L., \& Coltheart, M. (2012). Covert face recognition in congenital prosopagnosia: A group study. Cortex, 48(3), 344-352.

Rivolta, D., Palermo, R., Schmalzl, L., \& Williams, M. A. (2012). Investigating the features of the M170 in congenital prosopagnosia. Front Hum Neurosci, 6:45.( doi:10.3389/fnhum.2012.00045).

Rivolta, D., Woolgar, A., Palermo, R., Butko, M., Schmalzl, L., \& Williams, M. A. (2014). Multivoxel pattern analysis (MVPA) reveals abnormal fMRI activity in both the "core" and 
"extended" face network in congenital prosopagnosia. Front Hum Neurosci, 8, 925. doi: $10.3389 /$ fnhum. 2014.00925

Robbins, R. A., \& Coltheart, M. (2012). The effects of inversion and familiarity on face versus body cues to person recognition. J Exp Psychol Hum Percept Perform, 38(5), 1098-1104. doi: $10.1037 / \mathrm{a} 0028584$

Rossion, B., Caldara, R., Seghier, M., Schuller, A. M., Lazeyras, F., \& Mayer, E. (2003). A network of occipito-temporal face-sensitive areas besides the right middle fusiform gyrus is necessary for normal face processing. Brain, 126(Pt 11), 2381-2395. doi: 10.1093/brain/awg241

Schmalzl, L. (2007). Fractionating face processing in congenital prosopagnosia. (PhD), Macquarie University, Sydney, Australia. (BF242,S48)

Schmalzl, L., Palermo, R., \& Coltheart, M. (2008). Cognitive heterogeneity in genetically based prosopagnosia: A family study. Journal of Neuropsychology, 2(1), 99-117.

Schmalzl, L., Zopf, R., \& Williams, M. A. (2012). From head to toe: evidence for selective brain activation reflecting visual perception of whole individuals. Front Hum Neurosci, 6, 108. doi: $10.3389 /$ fnhum. 2012.00108

Song, S., Garrido, L., Nagy, Z., Mohammadi, S., Steel, A., Driver, J., . . Furl, N. (2015). Local but not long-range microstructural differences of the ventral temporal cortex in developmental prosopagnosia. Neuropsychologia, 78, 195-206. doi: 10.1016/j.neuropsychologia.2015.10.010

Steede, L., Tree, J., \& Hole, G. J. (2007). Dissociating mechanisms involved in accessing identity by dynamic and static cues. Visual Cognition, 15(1), 116-119.

Susilo, T., Yang, H., Potter, Z., Robbins, R., \& Duchaine, B. (2015). Normal body perception despite the loss of right fusiform gyrus. J Cogn Neurosci, 27(3), 614-622. doi: 10.1162/jocn_a_00743

Susilo, T., Yovel, G., Barton, J. J., \& Duchaine, B. (2013). Face perception is category-specific: evidence from normal body perception in acquired prosopagnosia. Cognition, 129(1), 88-94. doi: 10.1016/j.cognition.2013.06.004

Thomas, C., Avidan, G., Humphreys, K., Gao, F., \& Behrmann, M. (2009). Reduced structural connectivity in ventral visual cortex in congenital prosopagnosia. Nat Neurosci, 12(1), 29-31.

Urgesi, C., Berlucchi, G., \& Aglioti, S. M. (2004). Magnetic stimulation of extrastriate body area impairs visual processing of nonfacial body parts. Current Biology, 14, 2130-2134. 
Van den Stock, J., van de Riet, W. A., Righart, R., \& de Gelder, B. (2008). Neural correlates of perceiving emotional faces and bodies in developmental prosopagnosia: an event-related fMRI-study. PLoS One, 3(9), e3195. doi: 10.1371/journal.pone.0003195

Zhang, J., Liu, J., \& Xu, Y. (2015). Neural decoding reveals impaired face configural processing in the right fusiform face area of individuals with developmental prosopagnosia. $J$ Neurosci, 35(4), 1539-1548. doi: 10.1523/jneurosci.2646-14.2015 
Figure legends

Figure 1. Trial structure in the example where the study and the test bodies are presented in the same orientation. Note that the relation between the body and the screen size does not represent the real ratio, but it is for representational purposes only.

Figure 2. BIRT- accuracy (left), RTs (middle) and IES (right) variability across the two groups (* indicates a statistically significant difference; $p<.05)$.

Figure 3. Correlations between BIRT accuracy (\%), CFMT raw-scores (left) and CCMT raw-scores (right).

Table 1. CP's age and sex along performance on different "diagnostic" tasks. Performance on the MACCS Famous Face Test 2008 (MFFT-08), Cambridge Face Memory Task (CFMT-ASM) and Cambridge Face Perception Task (CFPT) relates to sex- and age- matched Australian controls (see Palermo et al., 2011; Bowles et al., 2009). Performance on the CFMT is also reported as compared to the originally published norms (CFMT-OR; Duchaine et al., 2006). CPs performance on the Australian version of the CFMT (CFMT-Aus; McKone et al., 2009) and on the Cambridge Car Memory Task (CCMT; Dennett et al., 2011) is also indicated.

\begin{tabular}{|c|c|c|c|c|c|c|c|c|c|c|c|c|c|}
\hline $\mathrm{CP}$ & Age & Sex & MFF] & -08 & CF & & & $\overline{C F}$ & IT-Aus & $\overline{C F}$ & & $\overline{\mathrm{CC}}$ & \\
\hline $\begin{array}{l}\mathrm{Cod} \\
\mathrm{e}\end{array}$ & $\begin{array}{l}\text { Year } \\
s\end{array}$ & $\mathrm{M} / \mathrm{F}$ & $\begin{array}{l}\text { \% } \\
\text { corre } \\
\text { ct }\end{array}$ & $\begin{array}{l}\text { Z- } \\
\text { scor } \\
\text { e }\end{array}$ & raw & $\begin{array}{l}\text { Z- } \\
\text { scor } \\
\mathrm{e}\end{array}$ & $\begin{array}{l}\text { Z- } \\
\text { scor } \\
\mathrm{e}\end{array}$ & $\begin{array}{l}\mathrm{ra} \\
\mathrm{w}\end{array}$ & $\begin{array}{l}\mathrm{Z-} \\
\text { score }\end{array}$ & $\begin{array}{l}\mathrm{ra} \\
\mathrm{w}\end{array}$ & $\begin{array}{l}\text { Z- } \\
\text { score }\end{array}$ & $\begin{array}{l}\mathrm{ra} \\
\mathrm{w}\end{array}$ & $\begin{array}{l}\mathrm{Z}- \\
\text { score }\end{array}$ \\
\hline $\begin{array}{l}\mathrm{M} \_6 \\
0\end{array}$ & 60 & $\mathrm{M}$ & 45 & $\begin{array}{l}- \\
1.0 \\
4\end{array}$ & 30 & $-\overline{2.49}$ & $\overline{3.63}$ & 40 & -2.42 & 42 & -0.03 & - & - \\
\hline $\begin{array}{l}\text { F_5 } \\
0\end{array}$ & 50 & $\bar{F}$ & 30 & -2.4 & 42 & $-\overline{1.39}$ & $\overline{2.03}$ & 37 & -2.82 & 50 & -1.14 & 53 & 0.358 \\
\hline $\begin{array}{l}\text { M_2 } \\
0\end{array}$ & 20 & $\mathrm{M}$ & 53 & $\begin{array}{l}- \\
2.0 \\
4\end{array}$ & 39 & $-\overline{1.89}$ & $\overline{2.40}$ & - & - & 48 & -0.79 & 51 & -0.77 \\
\hline $\begin{array}{l}\text { F_4 } \\
7\end{array}$ & 47 & $F$ & 6 & $\begin{array}{l}- \\
4.0 \\
5\end{array}$ & 39 & $\overline{1.81}$ & $\overline{2.40}$ & 41 & -2.28 & 52 & -1.41 & 45 & -0.76 \\
\hline
\end{tabular}




\begin{tabular}{|c|c|c|c|c|c|c|c|c|c|c|c|c|c|}
\hline $\begin{array}{l}\text { F_4 } \\
0\end{array}$ & 40 & $\mathrm{~F}$ & 35 & $\begin{array}{l}- \\
2.4 \\
3\end{array}$ & 37 & $-\overline{2.16}$ & $\overline{2}-64$ & 45 & -1.73 & 68 & -2.95 & 41 & -1.3 \\
\hline $\begin{array}{l}\mathrm{F}{ }_{3} 3 \\
\end{array}$ & 33 & $F$ & 23 & $\begin{array}{l}- \\
3.4 \\
9\end{array}$ & 38 & $\begin{array}{l}- \\
2.09\end{array}$ & $\overline{2.52}$ & 51 & -0.92 & 66 & -2.86 & 63 & 1.75 \\
\hline $\begin{array}{l}\text { M_5 } \\
3\end{array}$ & 53 & $\mathrm{M}$ & 27 & $\begin{array}{l}- \\
2.4 \\
6\end{array}$ & 30 & $-\overline{2.72}$ & $\overline{3}-\overline{3.63}$ & - & - & 36 & 0.53 & 54 & -0.41 \\
\hline $\begin{array}{l}\text { M_5 } \\
7\end{array}$ & 57 & $\mathrm{M}$ & 15 & -3.1 & 28 & $\begin{array}{l} \\
\end{array} .83$ & $\begin{array}{l} \\
3.90 \\
\end{array}$ & 45 & -1.73 & 70 & -1.93 & 35 & -2.69 \\
\hline $\begin{array}{l}\text { F_4 } \\
2\end{array}$ & 42 & $\mathrm{~F}$ & 17 & $\begin{array}{l}- \\
3.5 \\
5\end{array}$ & 42 & -1.5 & $\overline{2.03}$ & 38 & -2.69 & 26 & -0.7 & 65 & \\
\hline $\begin{array}{l}\mathrm{F} \_2 \\
3\end{array}$ & 23 & $F$ & 25 & -3.7 & 52 & -0.4 & $\begin{array}{l}- \\
0.83\end{array}$ & 46 & -1.6 & 50 & -1.53 & 54 & 0.5 \\
\hline $\begin{array}{l}\text { F_3 } \\
1\end{array}$ & 31 & $F$ & 37 & $\begin{array}{l}- \\
2.7 \\
2\end{array}$ & 51 & $\begin{array}{l}- \\
0.56\end{array}$ & $\overline{0}-95$ & 0 & - & 30 & 0.7 & 59 & 1.19 \\
\hline
\end{tabular}




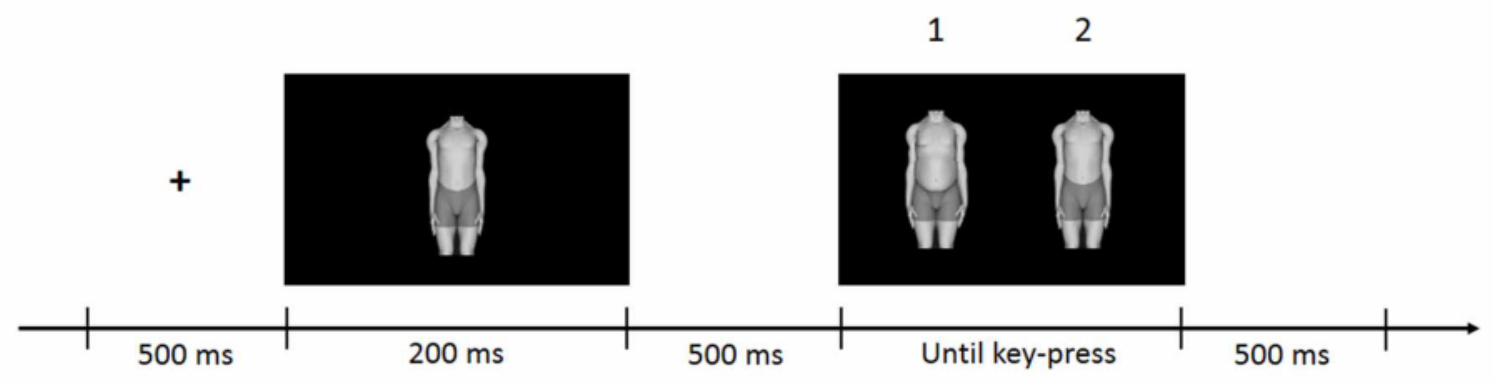

Time

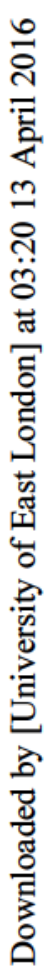



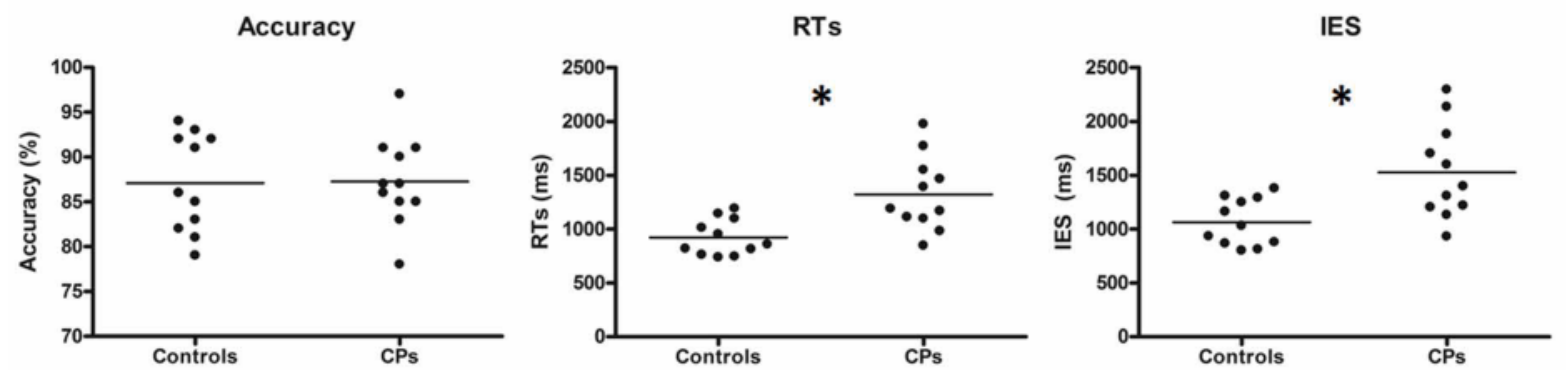

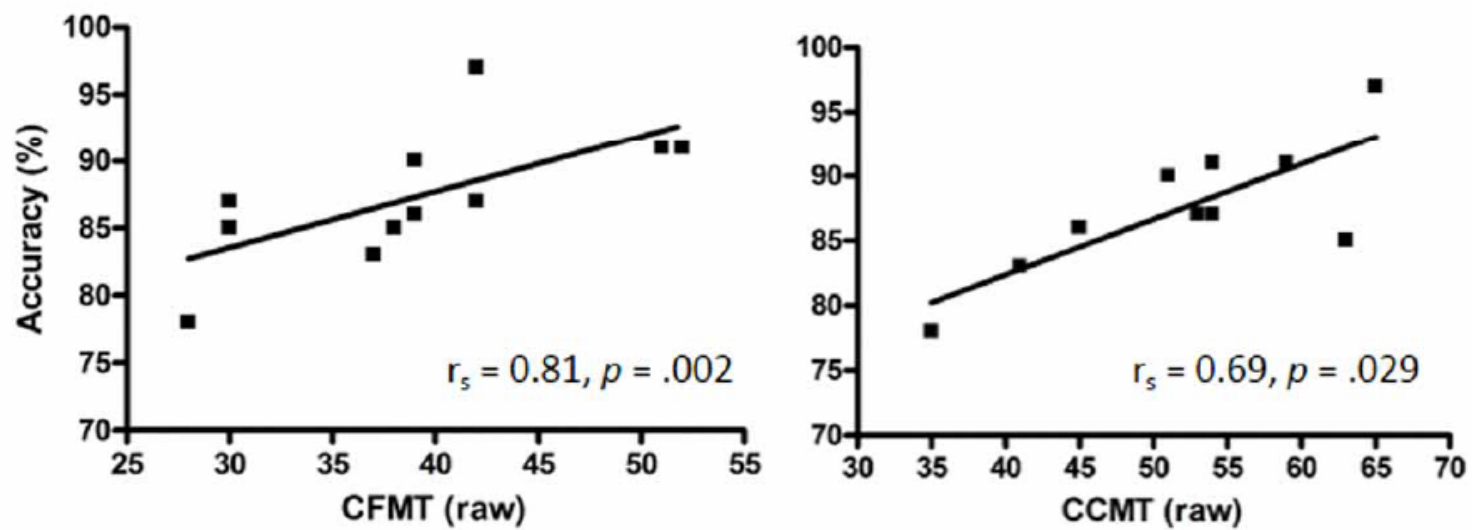